\title{
Salt fluoridation and oral health
}

\author{
Thomas M. Marthaler \\ Department of Preventive Dentistry \\ Periodontology and Cariology, Center \\ for Dentistry, University of Zurich \\ Zürich, Switzerland
}

\author{
Corresponding author: \\ Thomas Marthaler \\ Bellerivestr. 21 \\ CH 8008 Zürich \\ Switzerland \\ thomas.marthaler@uzh.ch \\ Tel.: + 41443817540 \\ Fax.: + 41446344301
}

Received: 26 February 2013

Accepted: 18 April 2013

Copyright (C) 2013 by

Academy of Sciences and Arts

of Bosnia and Herzegovina.

E-mail for permission to publish:

amabih@anubih.ba

\begin{abstract}
The aim of this paper is to make known the potential of fluoridated salt in community oral health programs, particularly in South Eastern Europe. Since 1922, the addition of iodine to salt has been successful in Switzerland. Goiter is virtually extinct. By 1945, the cariesprotective effect of fluorides was well established. Based on the success of water fluoridation, a gynecologist started adding of fluoride to salt. The sale of fluoridated salt began in 1956 in the Swiss Canton of Zurich, and several other cantons followed suit. Studies initiated in the early seventies showed that fluoride, when added to salt, inhibits dental caries. The addition of fluoride to salt for human consumption was officially authorized in 1980-82. In Switzerland 85\% of domestic salt consumed is fluoridated and $67 \%$ in Germany. Salt fluoridation schemes are reaching more than one hundred million in Mexico, Colombia, Peru and Cuba. The cost of salt fluoridation is very low, within 0.02 and $0.05 €$ per year and capita. Children and adults of the low socio-economic strata tend to have substantially more untreated caries than higher strata. Salt fluoridation is by far the cheapest method for improving oral health. Conclusions. Salt fluoridation has cariostatic potential like water fluoridation (caries reductions up to 50\%). In Europe, meaningful percentages of users have been attained only in Germany $(67 \%)$ and Switzerland (85\%). In Latin America, there are more than 100 million users, and several countries have arrived at coverage of 90 to $99 \%$. Salt fluoridation is by far the cheapest method of caries prevention, and billions of people throughout the world could benefit from this method.
\end{abstract}

Key words: Fluoride, Prevention, Dental caries, Salt.

\section{Introduction}

Fluorides are the main factor leading to the decline in the prevalence of dental caries, a decline which has surpassed all expectations. When "artificial" water fluoridation was introduced in 1945 in the USA and Canada, it was expected that caries prevalence would be reduced by as much as 50 percent. In the next two decades this prediction was found to be correct in many countries. The topical effects of fluorides, particularly when contained in dentifrices, have brought about a further caries decline in the industrialized countries. However, the fact that the lower social strata consistently show the highest levels of caries in the population has so far remained an unsolved problem. In analogy to fluoridated water, which confers partial protection independent of social conditions, salt with added fluoride was assumed to be 
as useful a carrier for human consumption as iodine has proved to be in the case of goiter since the early 1920s. It is the aim of this paper to update the scientific basis and the beneficial effect of fluoridated salt for human consumption.

\section{Iodized salt as a precursor of fluoridated salt}

In several valleys throughout the Alps, endemic goiter has been prevalent since prehistoric times. Between 1910 and 1920, insufficient intake of iodide was finally identified as the cause of endemic goiter. The key paper on the preventive effect of iodized salt was published by Marine and Kimball in 1917 (1). At that time, two local Swiss physicians started to add a few milligrams of iodide per $\mathrm{kg}$ of salt for human consumption in communities where goiter was prevalent. The success of this intervention was visible already after one year. The newborn children exposed to iodized salt had no symptoms of goiter, demonstrating the preventive effect of iodide added to salt and providing further evidence of the role of insufficient intake of iodide in goiter.

In 1922, the main Swiss salt factory developed the apparatus to add potassium iodide to salt. In the following years five of the 26 Cantons (which at that time still had a Cantonal Monopoly on the salt) decided to use exclusively iodized salt. By 1942, the number of cantons in which less than $50 \%$ of the salt was iodized had dwindled to seven (2). Goiter is now virtually extinct in Switzerland.

Dr. Hans J. Wespi, the son-in-law of the physician who had added iodide to the sacks of salt in 1918, was then Director of the Clinic for Gynecology and Obstetrics in the Cantonal Hospital at Aarau in 1946. He started to add sodium fluoride to already iodized salt which he gave to his patients who had or were expecting children. He did this on the hypothesis that soluble fluoride in salt would be as effective against caries as fluoride added to the drinking water. Salt fluoridation in Switzerland was therefore based on 25 years of successful iodization, since at that time scientific evidence was not available that fluoride has a cariostatic effect when contained in salt. The medical profession, however, was aware of the fact that salt had been shown to be a valuable vehicle for the micronutrient iodide. In the former "goiter areas", the public, as well as the medical profession, had noted that goiter became less severe, less frequent or disappeared altogether. It was logical that Wespi published his early papers $(3,4)$ on fluoridated salt not in a dental journal, but in the leading Swiss medical journal.

\section{Fluorides and teeth, early findings in North America}

From 1900 to 1938 research regarding the effects of fluoride on teeth - predominantly carried out in the USA - focused on gross malformations of tooth crowns. Affected crowns had brown or black stains and multiple fractures of the enamel. The malformations occurred endemically. Therefore, many dentists believed that the cause was to be found in the local drinking water. In fact, there were three publications, which, in 1931, identified high concentrations of fluoride in the drinking water as the cause of defective tooth crowns, then often called "mottled" teeth (now called enamel fluorosis).

On the other hand, Dean (5) found that children aged 9 years living in various counties in the State of North Dakota with 1.7 to $2.5 \mathrm{ppm} \mathrm{F}$ in the drinking water (where enamel fluorosis was frequent but not severe) had only 2.0 decayed teeth, while those in counties with 0.6 to $1.5 \mathrm{ppm} F$ in water had 4.2 decayed teeth. In 1939, Dean et al. (6) examined hundreds of children in 4 Illinois cities where drinking water contained 
either 0.2 ppm F or else 1.7-1.8 ppm F. Again, the children who had been consuming high fluoride water had less decayed teeth, namely 2.0 as opposed to 4.0 to 4.6 . Between 1941 and 1948 , at least 10 reports confirmed the caries-protective effect of $1.0 \mathrm{ppm} F$ in the drinking water. In these papers, the severity of caries was expressed as the number of Decayed, Missing, or Filled Teeth per individual, abbreviated to DMF-teeth, and this is still the best measure expressing the prevalence of caries.

In 1947, Arnold (7) compiled data on fluoride concentrations in drinking water and the averages of DMF-teeth in 12 to 14 year-old children in 27 Mid-Western US cities. These data documented that under conditions of 0.9 to $1.3 \mathrm{ppm} \mathrm{F}$ in the drinking water, the number of DMF-teeth was halved when compared to the teeth of children on water with 0.1 to $0.6 \mathrm{ppm} \mathrm{F}$. On the other hand, (mild) enamel fluorosis was present in 12 to $33 \%$ of the children on 0.9 and 1.3 ppm $\mathrm{F}$ in the drinking water. With fluoride concentrations below $0.7 \mathrm{ppm}$ F enamel fluorosis was far less frequent ( 0 to $11 \%$ ). The protective effect was shown to last at least until the age of 15 years.

In 1945, artificial fluoridation was started, with water treated to contain 1.0 milligrams of fluoride per liter, or $1.0 \mathrm{ppm} \mathrm{F}$, in three cities of the USA and Canada. For each fluoridated city a reference city was selected. After five years, the number of DMF-teeth in children aged six to nine was reduced by 26 to $60 \%$ in the three fluoridated cities, whereas in the three reference cities the number of DMFteeth remained more or less constant. Such experiments were repeated in several other cities with similar results: children who benefited from drinking water containing $1 \mathrm{ppm}$ fluoride had lower DMF-averages by approximately $50 \%$, and the protective effect was maintained at least up to the age of 15 years.

The reports on reduced caries prevalence in children after only five years of fluorida- tion induced many scientists to believe that early or even prenatal fluoridation would be indispensable to obtain the full protective potential of fluoride. In view of the almost complete absence of fluoride research in Continental Europe until the late 1950s, it is understandable that the American opinion prevailed for some years.

On the other hand, fluoride tablets, available since 1954 in Switzerland, were widely used for caries prevention. Many dentists working with the school dental services noted that caries incidence was also reduced in children who were already five to nine years old when they started to take the fluoride tablets. Swiss and German data became available providing evidence that fluoride tablets, given to six year-old children each school day, reduced dental caries experience in school aged children by 25 to $50 \%$.

\section{Changing concepts regarding the protective effect of fluoride}

In the period from around 1955 to 1970 , several developments improved the prospect for salt fluoridation.

- Use of fluoride in Switzerland began with program of daily intake of fluoride via tablets. After 2 to 3 years many dentists already noted a rapid decrease in caries incidence, not only in pre-school but also in schoolchildren. The idea that fluoride intake during the first two or three years of life is important for caries prevention was gradually abandoned.

- With the increasing duration of clinical studies on water fluoridation, it was observed that there must a considerable topical protective effect of fluoride on erupted teeth, even at relatively low fluoride concentrations around $1 \mathrm{ppm} F$. With increasing duration of water fluoridation it emerged that, for instance, 14-year-old children who had not consumed fluoridated water during their 
first five or six years of life had only slightly higher caries levels than children exposed to fluoridated water since birth.

- A considerable number of well-controlled clinical trials comparing caries increments in children using fluoridated toothpaste with those from children using the same toothpaste, but without fluoride, supported the opinion that the topical effect might even be the main anti-caries factor.

- Biochemical research based on analytical chemistry and enamel microhardness studies showed that within the 24-hour cycle there are hours during which submicroscopic demineralization dominates. This occurs during and after eating sugared food, which is fermented to lactic and other acids by the biofilm on the teeth, or dental plaque. Alternatively, there are hours during which remineralisation occurs, and this "healing" process of the slightly demineralized enamel is greatly enhanced by fluoride. In this dynamic situation, the presence of fluoride in the oral fluid is very important, as it catalyzes remineralisation of the enamel as well as dentine. Today, this mechanism is regarded as the main reason for the toothprotecting effectiveness of fluoride.

- As time went by, it had to be accepted that with the existing network of drink- ing water in Switzerland, water fluoridation is difficult or impossible to realize for technical and legal reasons related mainly to a multitude of small water supply systems. A political move for the introduction of water fluoridation was successful only in Basel, serving $0.3 \%$ of the Swiss population from 1962 to 2003 (8).

\section{Clinical caries studies with fluoridated salt in Western Switzerland}

In Western Switzerland, the Canton of Vaud, which has its own salt factory, decided to add fluoride to the salt. This Canton (half a million inhabitants in 1970) had had a scheme of daily distribution to schools of one $1.0 \mathrm{mg}$ fluoride tablet since the early 1960s. On the advice of Prof. Mühlemann of the Zurich University Dental School, the Cantonal Salt Commission of Vaud decided in 1970 to add $250 \mathrm{mgF}$ to salt for human consumption and recommended that fluoride tablets should not be used any longer in the Canton. Since 1970 salt with 250 ppm F has been used in households, bakeries and all institutions running their own kitchens. Accordingly, fluoridated salt has been virtually the only salt sold in the Canton of Vaud. In the course of time with mobility and rural shopping centres on the increase, the rather strict situation regarding the use of the 250

Table 1 The number of DMF-teeth per 12-year-old child in the three reference communities with no or limited exposure to F-salt and in the three communities of the Canton of Vaud where the use of fluoridated salt began in 1970

\begin{tabular}{llll}
\hline Year & Reference limited F-exposure & Using 250 ppm F, F-salt, VD & \% lower under F-salt \\
\hline 1970 & 6.97 & 5.61 & 20 \\
1974 & 5.24 & 4.30 & 18 \\
1978 & 4.47 & 3.93 & 12 \\
1982 & 4.87 & 2.92 & 40 \\
1986 & 3.17 & 2.12 & 30 \\
1990 & 2.29 & 1.88 & 18 \\
\hline
\end{tabular}

VD= Canton of Vaud; Smallest numbers of children: 34, 41, 58, all other sample sizes between 63 and 189. Source of data: (9). 
ppm F salt in Vaud was "diluted" to some extent. Nevertheless, surveys studying urinary excretion in the main city of Lausanne confirmed that fluoride concentrations were still similar to those found in regions with fluoridated water in similar climates. Table 1 shows the results obtained in children at the age of 12 years (9).

The children from the three Vaud communities close to the cantonal border had consistently lower averages of DMF-teeth than those in the three reference communities outside the Canton of Vaud. Regarding the initial examinations in 1970, lower caries experience was to be expected in view of the fact that the Vaud children had been given $1 \mathrm{mg}$ fluoride via tablets distributed daily at school for many years. In all six surveys from 1970 to 1990 , carried out at four-year intervals, the Vaud children had consistently lower DMFT-averages when compared to the non-Vaud children, as indicated by the statistical significance in the sign test. The DMFT counts of the 8 and 10-year-old children resulted in the same pattern: the eight averages from Vaud were consistently lower than those of the reference children. In addition, 14-year-old children were examined in Yverdon, another town in the Canton of Vaud with a population of about 20,000. The average number of DMF-teeth was 8.47 (number of children examined: 68) in 1970 but decreased to $2.99(\mathrm{~N}=101)$ in 1988.

With respect to the caries decline in the reference communities, several factors are to be considered. Within the school dental service, comprising one free dental examination per year and subsidized restoration of cavities, school committees implemented educational program of various intensity:

- Regular toothbrushing exercises with topical fluoride were organized.

- Information on prevention was made available through leaflets.

- In some of the communities, fluoride tablets were distributed until 1983.
Accordingly, the reduction in the caries levels in the reference communities is easily explained by the educational program in school.

In 1974, a second epidemiological longterm study was begun in the Canton of Glarus. It lasted until 1996 and confirmed the cariostatic effectiveness of fluoride when added to salt (10). The long term results were summarized (11). The Swiss Dental Association and subsequently the Swiss Academy of Medical Sciences then agreed that for mass prevention of caries in Switzerland, the fluoride concentration in the domestic salt should be raised to $250 \mathrm{ppm} \mathrm{F}$ ( $250 \mathrm{mg}$ fluoride per kg of salt). This is equivalent to $1.0 \mathrm{mg}$ of fluoride contained in 4 grams of salt. The respective resolutions in the involved committees and by the Health Ministry were passed in 1980 to 1982. Interestingly, there was little opposition to the higher concentration. In fact the market share of fluoridated salt in Switzerland has since increased consistently (12).

In 1992, the marketing department of the main salt factory started to reduce the package size of domestic salt from the usual $1 \mathrm{~kg}$ to $500 \mathrm{~g}$ packages. Within three months after this change of policy, the market share dropped from 75\% (September 1992) to $46 \%$ (November 1992). After this serious setback, it was decided that the $250 \mathrm{ppm} \mathrm{F}$ salt should be available in all package sizes up to $1 \mathrm{~kg}$ whereas the unfluoridated varieties were restricted to the 500 gram packages. In January 1994, immediately after re-introduction of the $1 \mathrm{kgF}$ salt package, the market share started to rise again and by 1998 leveled out at $86 \%$ (12).

\section{Evidence for the caries-preventive effect of fluoridated salt in adults}

It is generally accepted that the cariostatic action of fluorides continues during adult life. In this case it is exclusively the local mode of action of fluoride (the accelerated remineralisation of demineralized enamel 
Table 2 Swiss Army Recruits subdivided according to the level of previous prevention

\begin{tabular}{|c|c|c|c|}
\hline \multicolumn{4}{|c|}{ Line 1: no or only a few communities with OPS in the Cantons } \\
\hline \multicolumn{4}{|c|}{ Line 2: about half of the communities with OPS in the Canton } \\
\hline \multicolumn{4}{|c|}{ Line 3: most communities with OPS in the Canton } \\
\hline \multicolumn{4}{|c|}{ Line 4: closely supervised OPS in the Canton of Zurich } \\
\hline \multicolumn{4}{|c|}{ Line 5: universal fluoridation via salt, Canton of Vaud, VD; $250 \mathrm{ppm}$ since 1970 when the later recruits were 5 years old } \\
\hline \multicolumn{4}{|c|}{$\begin{array}{l}\text { Line 6: fluoridated water, Canton of Basel City (1.0 ppm F since 1962, which was } 13 \text { years before the later recruits were } \\
\text { born) }\end{array}$} \\
\hline \multirow{2}{*}{ Prevention level } & \multirow{2}{*}{$\mathrm{n}$ of recruits } & \multicolumn{2}{|c|}{ Caries experience, average per recruit } \\
\hline & & DMFT & DFS \\
\hline 1 No prevention in school & 157 & 11.3 & 21.3 \\
\hline 2 Little prevention in school & 302 & 10.9 & 20.3 \\
\hline 3 Good prevention at school & 123 & 9.1 & 17.0 \\
\hline 4 Canton of Zurich, ZH & 92 & 9.3 & 17.3 \\
\hline 5 Canton Vaud, VD, F-salt & 56 & 7.1 & 11.6 \\
\hline 6 Ct. Basel, F-water & 23 & 9.0 & 15.4 \\
\hline All recruits & 753 & 10.1 & 18.8 \\
\hline \multirow[t]{2}{*}{ Stand. dev. $\mathrm{N}=753$} & & 4.9 & 12.5 \\
\hline & \multicolumn{3}{|c|}{ Results of the analyses of variance F-tests between/within groups } \\
\hline F: between/within, $p$ & $<0.001$ & $<0.001$ & $<0.001$ \\
\hline
\end{tabular}

and dentine) which leads to the protective effect. Epidemiological data are available from Switzerland and Hungary.

In 1985, 753 recruits of the Swiss army (most of them 20 years old) were examined. A total of 57 recruits had grown up in the Canton of Vaud, where the salt has contained 250 ppm fluoride since 1970. Table
2 shows they had an average of 7.1 DMFT. The recruits from water-fluoridated Basel had an average of 9.0 DMFT, while all others had between 9.3 and 11.3 DMFT, depending on whether or not preventive program had been implemented during school age (13).

Table 3 shows that the DMFT of the Vaud recruits was significantly lower than

Table 3 Confidence limits (LowL and UppL) of DMF-findings and t-tests between Vaud and the other groups exposed to different levels of prevention or to fluoridated water (see Table 2)

\begin{tabular}{lllllllll}
\hline Line Table 2. level of prevention & $\mathrm{n}$ & Mean DMFT & LowL & UppL & Comp. & Difference & $\%$ diff. & $\mathrm{p}$ \\
\hline 1. No or few OPS & 157 & 11.3 & 10.5 & 12.1 & vs VD & -4.20 & -4.20 & $>0.001$ \\
2. OPS for about 50\% & 302 & 10.9 & 10.3 & 11.5 & vs VD & -3.80 & -3.80 & $>0.001$ \\
3. OPS for majority & 123 & 9.1 & 8.2 & 10.0 & vs VD & -2.00 & -2.00 & $>0.001$ \\
4. Canton of Zurich. good OPS & 92 & 9.3 & 8.3 & 10.3 & vs VD & -2.20 & -2.20 & $>0.001$ \\
5. Canton of Vaud. VD. F-salt & 56 & 7.1 & 5.8 & 8.4 & - & - & - & - \\
6. Ct. Basel. BS. F-water & 23 & 9.0 & 7.0 & 11.0 & vs VD & -1.90 & -1.90 & $\approx 0.001$ \\
\hline
\end{tabular}

Source of data: (13). Menghini et al. 1991; see also Table 2. 
that of any of the other groups, including the 23 recruits from water-fluoridated Basle. This study shows clearly that the supply of fluoride, used by the entire population, has resulted in an improved level of dental health which was maintained into young adulthood.

\section{Salt fluoridation and enamel fluorosis in Switzerland}

In Switzerland, the sale of fluoride tablets started in 1953. A large number of dentists used the tablets in their own families with great success. Several small cantons decided to distribute fluoride tablets on each school-day. High exposures to fluoride occurred in connection with the early recommended dosage of fluoride (first year of life: $0.25 \mathrm{mgF}$, then increasing each year by 0.25 $\mathrm{mgF}$ to $1.0 \mathrm{mgF}$ from the fourth year of life onwards) and resulted in slight and sometimes easily visible enamel fluorosis. New recommendations for a lower dosage were made in 1960: from the eruption of the first primary tooth until 23 months of age: 0.25 mg F; 24 months to 48 months: $0.5 \mathrm{mg}$ F; 48 months to 71 months: $0.75 \mathrm{mg}$ F; from age 6 to adulthood: $1.0 \mathrm{mgF}$. After introduction of the lower dosage, children with easily visible enamel fluorosis became increasingly rare but studies recording the actual prevalence were not carried out in those years.

In the context of the epidemiological caries studies in Vaud, De Crousaz (14) assessed enamel fluorosis frequencies of the upper incisors among children aged 6-8y and $9-13 y$ in water-fluoridated Basel (fluoride added from 1962 until 2003), in the Canton of Vaud and in two reference towns outside Vaud. The sensitive index of Thylstrup and Fejerskov (15) was used. Mouth frequencies of enamel fluorosis were at $36 \%$ at age 6-8 and at $38 \%$ at age $9-13$. In the Canton of Vaud (universal salt fluoridation) mouth frequencies were at $37 \%$ and $38 \%$ and in the reference children at $25 \%$ and $26 \%$, respectively. Non-fluoride opacities occurred in $18 \%$ of the Basle children, in $7 \%$ of the Vaud children and in $25 \%$ of the reference children. In the entire survey, only one child (among a total of 1242) showed a TF-score 3 on the left central incisor.

Studies between 1982 and 1996 in five different locations resulted in frequencies between $13 \%$ and $28 \%$ (16). In their own extensive study, Steiner and Menghini (16) assessed enamel fluorosis in 1087 schoolchildren (age 9-10y) and 964 military recruits (age 19-21y) in the years 1995-69 and in 2004-2005. The subjects took part in epidemiological surveys for dental caries organized by the Clinic for Preventive Dentistry, Periodontology and Cariology, Dental Centre, University of Zurich. In their summary the authors stated: "Fluoride-associated opacities of TF score 2 were only observed in approximately $1 \%$ of the participants. One examiner noted a TF score 3 in a single individual. Fluoride-associated opacities therefore are not a cosmetic problem and certainly not a public health concern".

To complete the picture it is important to know that in Switzerland fluoride tablets are still on sale in pharmacies without prescription, but only very few families still use them. Fluoride toothpastes (up to $1500 \mathrm{ppm} \mathrm{F}$ ) are regularly used. For small children up to six years, toothpastes with less than 500 ppm F are recommended. Daily fluoride rinses are used by $20 \%$ of Swiss children; another $20 \%$ brush their teeth with concentrated fluoride gels $(1.25 \% \mathrm{~F})$ once a week. Respective information is given in the schools at regular intervals. Urinary excretion studies in the Canton of Vaud showed that fluoride levels in urine obtained from adolescents were in the optimal range in terms of both fluoride concentrations and fluoride excretion due to the universal use of fluoridated salt (17). Children at age 10-14y in Lausanne (the Capital of the Canton of Vaud) had urinary 
concentrations of $1.3 \mathrm{ppm} F$ after lunch, 1.1 ppm $\mathrm{F}$ at night and $0.8 \mathrm{ppm} \mathrm{F}$ in the morning. Enamel fluorosis is certainly not a problem in Switzerland.

\section{Fluoridated salt in other European countries}

In 1968, K. Toth of Szeged (a city in Southern Hungary), Professor of Conservative Dentistry, started clinical studies in several towns, using salt containing 200 or $250 \mathrm{mgF} /$ $\mathrm{kg}$ (18). Since 1972, two further communities were added and were provided with salt containing 350 ppm F. After 1981, all salt in the fluoridated towns contained $350 \mathrm{ppm}$ F. The last DMFT-averages are presented in Table 4. They provide further evidence for the cariostatic effect of fluoride added to salt.

Radnai and Fazekas (19) examined the teeth of Hungarian adults in 1991. The reference subjects (group A) consisted of subjects who had had no significant fluoride exposure. The second group of adults, B, had been living in the towns and villages which were provided with fluoridated salt from 1966 to 1985 (initially with 250 or 200 ppm; after 1972 increasingly, and from 1979 to 1985 consistently, with $350 \mathrm{ppm} \mathrm{F}$ ) (18, 19). Group $C$ had been lifetime residents in a town with the naturally optimal content of $1.1 \mathrm{ppm} \mathrm{F}$ in the drinking water (Kunszentmarton). The total number of subjects examined in the age group 28-37 years in the three groups was 205. Reference group A had 16.5 DMF-teeth, group B 13.4.The subjects using $1.1 \mathrm{ppm} F$ water since birth had only 9.7 DMFT-teeth (group C). They had received the supplemental fluoride in the water during their whole life, whereas in group B the fluoride intake from salt started only at age 3 to 12 years and lasted only 19 years. In spite of the shorter exposition to fluoride, group B had 3.1 less DMFT when compared to the 16.5 DMFT in the reference group A.

In the youngest age group (18-27 years), the DMFT averages for groups A, B and C were $13.8,7.9$ and 5.4 , respectively. The mean DMFT of group B was much closer to the mean of group A. This would be expected since these young adults had exposure beginning at birth or at the age of three years at the latest. These young adults did not receive fluoridated salt during the six years prior to the dental examination in 1991 because the production of fluoridated salt was stopped in 1985.

The Swiss and Hungarian surveys both support the hypothesis that the beneficial effect of fluoride in salt extends into adulthood, and that immigrants into salt fluoridated communities also benefit from fluoride. In spite of comprehensive research in and around Szeged and several political moves to introduce salt fluoridation for the whole country, this measure has not been implemented in Hungary.

France was the second European country adopting salt fluoridation in 1986 . The resolution for this measure was in part based on a series of publications in French on fluori-

Table 4 Average counts of diseased teeth per child in Southern Hungary and changes from 1966-1982

\begin{tabular}{lllll}
\hline Group (Age) & Initial & Use of F-salt & Final & Lower \\
Average caries & $1966-1982$ & Average caries & 16 years later (\%) \\
\hline \multirow{2}{*}{$5-6, \mathrm{dmft}$ (primary teeth) } & $5.19^{*}$ & No & 6.70 & - \\
& 6.78 & Yes & 3.16 & 53 \\
\hline \multirow{2}{*}{$13-14$, DMFT } & $7.33^{*}$ & No & 10.27 & \\
& 8.21 & Yes & 3.29 & 60 \\
\hline
\end{tabular}

${ }^{*}$ Children from 3 reference villages: Age 2-6 and 12-14 from Table 82, all other data from Table 111 (18). 
dation in Switzerland (Frey and Maeglin ed. 1982: Fluoruracion du sel pour la prevention de la carie, Revue mens. suisse Odonto-stomatol. Vol. 92, No. 4, April 1982, 130 pages), and on other evidence of the cariostatic effect of fluoride when added to salt. Due to a nationwide campaign for its use, the market share in France attained 50\% in 1991 and even $60 \%$ in 1993 (20). However, due to the lack of continued promotion, the market share dropped to $27 \%$ in 2003 and was below $10 \%$ in 2010. In terms of the French population of now roughly 60 million this means that after 1993, when there were 36 millions users of fluoridated salt, their number has dwindled to less than six million by 2012. Lack of continued promotion of fluoridated salt was the main reason for the decreasing market share.

Germany started to import fluoridated salt from France in 1991. After a few years, the government authorized production of F-salt by German refineries. The salt industry promoted the switch from iodized salt to domestic salt with both added iodide and fluoride. The information campaign included dietary advice for the prevention of caries and recommendations regarding oral hygiene. A committee of university professors and practicing dentists met once a year with a public relations agency, who produced and updated leaflets and other material promoting dental health.

The cost of the promotion in Germany has been in the order of magnitude of $100,000 €$ per year. On the other hand, the cost of adding fluoride may be assumed to be $200,000 €$ per year (as explained at the end of this paper). In markets and shops, the price of fluoridated salt in Germany is 5 or 10 cents higher per package of $500 \mathrm{~g}$ of salt. Due to the continued well-planned information campaigns, including general rules for oral hygiene and dietary measures, the market share of F-salt rose from approximately $20 \%$ in 1997 to $50 \%$ in 2000 and, since 2007 , it has leveled out just below 70\% (21). In comparison with France's breakdown of fluoridated salt usage, the German campaign has been a real success.

In the Czech Republic, it was reported that $35 \%$ of the domestic salt is now fluoridated (22). This is somewhat surprising since the price of fluoridated salt there is almost twice as high as that of the unfluoridated salt. Part of the fluoridated salt sold in the Czech Republic is imported from neighbouring countries, mainly Germany.

In other countries (for example Austria, Spain, Slovakia) fluoridated salt is used on a very limited scale. The sale of fluoridated salt would be legal in Greece and in the Netherlands (22) but there seems to be no interest in this preventive method. On the other hand, the vast majority of dentifrices are fluoridated all these countries. While the health authorities seem to have some knowledge regarding the benefits of fluorides, they appear to be unaware of their full cariostatic potential. Unfortunately, many dental experts are of the opinion that fluoridated toothpastes are sufficient to provide protection from caries. From a public health point of view, however, additional measures are necessary, above all in order to reach socially disadvantaged or remote groups in many countries. Of the world's current population of seven billion, three to five billion people have no or very limited access to prevention or, more specifically, to caries-preventive fluorides. Caries is still destroying teeth in children, adults and old people world-wide - only in minors and young people of a minority of countries has caries prevalence been reduced on a public health scale.

\section{Salt fluoridation in the Americas}

The "First International Symposium on Salt Fluoridation" took place in 1977 in the city of Medellin, Colombia. Participants came from South and North America and a few 
from Europe, mainly Switzerland. The Scientific Publication No. 501 "Salt Fluoridation" (23) documents the early interest in salt fluoridation in this part of the world. The Symposium site was well-chosen: in this country, a clinical trial had compared the effect on caries of three fluoride regimens:

- Fluoride in water $(\mathrm{NaF})$ ) at $1.0 \mathrm{ppm} \mathrm{F}$ (in San Pedro);

- Sodium fluoride $(\mathrm{NaF})$ added to salt at 200 ppm F (in Armenia);

- Calcium fluoride $\left(\mathrm{CaF}_{2}\right)$ added to salt at 200 ppm F (in Montebello);

- No fluoride added, reference (Don Matias). The initial dental examinations in 1964 showed that in all four towns chosen for the study, caries experience was similar (24, see Table 5). Addition of fluoride to salt was undertaken in a laboratory at the University of Antioquia, which also supervised the examinations for caries (age group 6 to $14 \mathrm{y}$ ) and assessed urinary fluoride concentrations. The study was carried out under the guidance of the local dental staff of the University of Antioquia NIDR-USPHS, and Dr. G. Gillespie of the Pan-American Health Organization (the American Regional Office of the World Health Organization in Geneva). Table 5 shows the initial (1964) and final (1972) DMFT averages in the 10 and 12 year old children. The reductions obtained were close to $50 \%$, ranging from 47 to $58 \%$ (24).

The fluoride concentrations in urine ranged between 0.50 and $0.80 \mathrm{ppm} F$ in the CaF2-group (Armenia), and between 0.64 and 0.87 in the NaF group (Montebello). This was somewhat below the concentrations in water-fluoridated San Pedro (0.9 to $1.2 \mathrm{ppm} \mathrm{F}$ ). In the reference town Don Matias, the concentrations were at 0.18 and $0.27 \mathrm{ppm}$ F. There were no differences between the cariostatic effectiveness between the chemicals used for fluoridation. Notably, caries was equally inhibited whether the rapidly soluble fluoride $(\mathrm{NaF})$ or the almost insoluble compound ( $\mathrm{CaF} 2)$ was added to food. In the reference community, there was virtually no change in caries prevalence.

In the Colombian towns, domestic salt was under government control at that time and very little industry-processed food existed, whereas today salt is often added to food before it is offered to the customer. Such pretreated food was then simply not available or on sale only in cities. Thus, virtually all of the salt ingested was fluoridated in the two respective groups. The Colombian results became rapidly known in Latin American states, and several countries began to add fluoride to salt for human con-

Table 5 DMFT-averages per child in the 4 Colombian towns and percent reductions of DMF-averages in 1964 (when addition of fluoride to water and salt started) until 1972

\begin{tabular}{llll}
\hline Age & 1964 & 1972 & Reduction (\%) \\
\hline 10 years & & & 53 \\
\hline F-water, NaF & 6.21 & 2.91 & 58 \\
NaF in salt & 5.33 & 2.23 & 57 \\
CaF2 in salt & 5.70 & 2.47 & - \\
No added fluoride & 6.96 & 6.91 & 57 \\
\hline 12 years & & & 48 \\
\hline F-water, NaF & 9.48 & 4.10 & 47 \\
\hline NaF in salt & 8.59 & 4.50 & - \\
\hline CaF2 in salt & 9.44 & 4.96 & 11.03 \\
\hline No added fluoride & 10.72 & & \\
\hline
\end{tabular}

Source of data: (24). 
sumption. Costa Rica and Jamaica were the first to start in 1996/1997.

In Jamaica, which as an island has a partially isolated population, there is only one factory which refines the raw sea salt purchased from several nearby Caribbean islands. Addition of iodide had been introduced already in the 1970s, and goiter disappeared from the island. The refinery built a fluoridation apparatus which spread a concentrated fluoride solution (containing also iodide) on the salt on a conveyor belt passing underneath. At the Health Ministry, there was a debate as to whether salt without fluoride should be on sale besides the salt with both iodide and fluoride. After some discussion, the manager of the salt refinery suggested fluoridating all salt for human consumption when a consensus was reached that fluoridated salt was the better product from a standpoint of public health and marketing. Accordingly, the decision was that the regular salt should contain both micronutrients. The factory manager then conceded that for anyone insisting on using unfluoridated salt for cooking, the enterprise would keep unfluoridated salt on stock, but that the customary distribution channels would be uniformly provided with the fluoridated (and iodized) salt.

Caries levels in Jamaica were assessed in 1986 and 1995 (25). In 12 year-old children, the number of DMF-teeth was re- duced from 6.7 to 1.1. A reduction of $69 \%$ was even found in 15 year old children who had started to benefit from fluoride after the age of seven or eight years. Investigations regarding factors that may have influenced the caries experience of Jamaican children led to the conclusion that the fluoride in the salt must have been the main reason for the dramatic decrease in caries prevalence on the island (26). In 2008, follow-up assessments of urinary fluoride in children at age three to five were made. Urinary fluoride concentrations in nocturnal collections were $1.33 \mathrm{ppm}$ $\mathrm{F}$ (urban children) and $1.26 \mathrm{ppm} \mathrm{F}$ (rural children) and at daytime 1.28 and $1.26 \mathrm{ppm}$ F, respectively (27). From a large number of studies it is known that under conditions of optimal levels of fluoride in drinking water, urinary fluoride concentrations are in the range 0.9 to $1.2 \mathrm{ppm}$ F. Fluoride excretions per hour and per 24 hours were also within the optimal range.

The following favourable external circumstances facilitated the introduction of universal salt fluoridation in Jamaica:

- Universal iodization had been introduced before 1980;

- There is only one salt refinery on the island (=country in this case);

- Fluoride concentrations were below 0.3 ppm $\mathrm{F}$ in $95 \%$ of the drinking water;

- All drinking water had concentrations below 0.7 ppm F;

Table 6 Average number of DMF-teeth per child in four American countries before and 8 to 12 years after the start of salt fluoridation

\begin{tabular}{llllll}
\hline \multirow{2}{*}{ Country, age of children } & First survey & \multicolumn{3}{l}{ Last survey } & Reduction of DMFT in \% \\
\cline { 2 - 5 } & Year & DMFT & Year & DMFT & 84 \\
\hline Jamaica, 12 years & 1986 & 6.7 & 1995 & 1.1 & 69 \\
Jamaica, 15 years & 1986 & 9.5 & 1995 & 3.0 & 72 \\
Costa Rica, 12 years & 1987 & 8.4 & 1999 & 2.5 & 44 \\
Mexico, 12 years & 1988 & 4.4 & 1997 & 2.5 & 42 \\
Uruguay, 11-14 years & 1991 & 4.1 & 1999 & 2.4 & \\
\hline
\end{tabular}

Source of data: (22) 
- There was literally no opposition to the addition of fluoride to salt.

Countries with similarly high coverage of almost the entire population are Colombia, Costa Rica, Mexico and Uruguay; the population of these four countries is approaching 160 million. These countries have now up to 20 years of documented use of fluoridated salt. Results regarding dental caries are shown in Table 6.

Fluoridated salt is also available in countries such as Belize, Bolivia, Cuba, Dominican Republic, Ecuador, Peru, Venezuela; a few other countries are in the process of implementing salt fluoridation. In Latin America, bakers mostly use the same small salt packages of $0.5 \mathrm{~kg}$ as the households. Restaurants also frequently use small salt packages. That means that even when only the salt in small packages is fluoridated, it provides fluoride beyond the households, which enhances the effectiveness against caries. Details of the situation in the Americas up to 2008 were presented in detail by Estupinian (28).

\section{Approximate costs of salt fluoridation}

General problems to be considered for making plans prior to the introduction of a salt fluoridation scheme have been discussed extensively in a previous publication. Initial information available in each country on salt production and distribution is relatively easy to obtain:

- Is there already a program of salt iodization?

- How many major producers of salt are there in the country?

- How much of the salt is imported? From where?

- How many drinking water systems with fluoride concentrations above $0.8 \mathrm{ppm} \mathrm{F}$ exist in the country?

In addition to these basic questions, many details must be clarified. These are listed in the respective paper (11). On the basis of this information, cost estimates can be made. The cost of stainless batch mixers for one ton of salt amounts to tens of thousands of $€$ (Euro). Local solutions for mixers, particularly smaller ones, may be constructed at lower prices. For sufficient capacity, for instance for one million users, two or three mixers may be necessary, which may cost $100,000 €$. For quality control, a laboratory equipped for simple analytical chemistry is also necessary. It may be integrated in the laboratory for control of iodization. These costs are necessary only in the first year.

The cost of the fluoride (using sodium fluoride, $\mathrm{NaF}$ ) necessary for one ton of salt lies between 1.38 and $2.76 €$. Further costs are for technical and laboratory personnel, needed for operating the mixer and working in the analytical laboratory for quality control and technical maintenance. For a population of one million, which "uses" or "consumes" approximately six kg salt per year and capita, the calculations indicate a total cost between 0.023 and $0.038 €$ per year and person. Details of the respective calculations were presented in an earlier paper (29).

Promotion costs for implementing F-salt instead of unfluoridated salt are variable. As indicated above, about $100,000 €$ per year is spent to convince roughly two-thirds of the German population to use fluoridated salt. $100,000 €$ divided by a population of 80 million is equivalent to $0.00125 €$, or 0.125 $€$-cents per capita and year. This is roughly 4 times the cost of F-salt production and quality control. The example of the dormant salt fluoridation in France shows that promotion costs are indispensable, although they exceed the cost of production costs during the initial years. The total cost for a successful salt fluoridation scheme, while maintaining free choice, would thus range between $0.024(=0.023+0.00125)$, and $0.04 €$-cents (or $0.039 €$-cents; $=0.038+0.00125$ ). In these estimates, the cost of building the fluoride addition apparatus is not considered. It is 
evident that salt fluoridation is by far the cheapest method of caries prevention.

Universal salt fluoridation has only been implemented in Jamaica (close to 100\%) and in Uruguay (95\%). In the majority of iodization program, such a high coverage is the rule. This is justified because the consequences of insufficient iodide intake are very serious: disfiguring goiter, oligophreny, idiocy. One may point out, on the other hand, that progressive destruction of the teeth and their roots can lead to situations which are potentially dangerous for health in general: infections, abscesses, tooth loss and bacteraemia with unforeseeable consequences affecting work and income. In view of the public health aims, use of universal salt fluoridation is clearly indicated: it is a safe, effective and extremely cheap health measure. On the other hand, restoration of decayed teeth and tooth replacements is very expensive, amounting to about $10 \%$ of all medical costs.

In Switzerland there is free choice between "pure" salt and salt with iodine, fluoride or both micronutrients. However, it has been the aim of both the Swiss health authorities and the Swiss Dental Association to motivate the greatest possible proportion of the population to use the iodized and fluoridated salt regularly. Since $1998,85 \%$ of the domestic salt has been fluoridated. The following factors may have played a role in this success:

- Salt iodization was a great success in Switzerland for both the medical community and the public at large.

- The idea of salt fluoridation was closely connected with the idea of using salt as a carrier of a micronutrient, as in the case of iodide.

- A few middle-sized food chains offer only F-I-salt since the other varieties are purchased by less than $10 \%$ of the customers.

- The price of salt is the same, regardless of whether it contains additives or not.
Contrary to the situation in "water fluoridation countries", opposition against fluoridated salt has been minor and has been almost totally absent for 30 years. When the fluoride concentration was increased from 90 to 250 ppm F, the Swiss Dental Association created a simple leaflet stating that people should continue to use the "new" fluoridated salt, in view of its stronger anticaries effect. The population followed this advice and used fluoridated salt increasingly.

\section{High caries prevalence in the low social strata}

Caries prevalence has consistently been highest in the lowest social strata. Could salt fluoridation be the right vehicle to improve this deplorable situation? It is a fact that in the low social strata, preventive recommendations and practices are not adopted to a sufficient degree. For example, if only $40 \%$ of domestic salt is fluoridated, the greatest part of this salt will be consumed by the population in the upper social strata. In order to attain benefit for all social levels, the great majority of the population must become regular users of fluoridated salt. In order to reach the lower strata, a percentage of fluoridated salt of at least $67 \%$ is necessary. In Europe only two countries, Switzerland and Germany, have attained a coverage exceeding two-thirds of the population. In these two countries, part of the lower strata population actually uses fluoridated salt, particularly in Switzerland where approximately $85 \%$ of the domestic salt is fluoridated. In the other European countries, where the use of fluoridated salt is below $50 \%$, the beneficial effect on a public health scale must be considered to be minimal. It should be noted that EU-regulations permit addition of fluoride to salt (and to water) (22).

Obviously the overall situation is unsatisfactory in most European countries. The great challenge for each country would be to 
find means and ways to increase the percentage of people using - exclusively or at least predominantly - the fluoridated variety of salt. In addition to the promotion of public health campaigns on all levels, further possibilities should be considered:

- Use of fluoridated salt for bread. This single step would increase the number of daily contacts of fluoride with the teeth; whenever a piece of bread is eaten, the fluoride concentration in the saliva is raised to approximately one ppm $\mathrm{F}$, whereas in resting saliva it is only at about 0.02 ppm F.

- Use of fluoridated salt in restaurants, canteens and institutions for the aged. This would specifically increase the number of "fluoride contacts" in the adults.

- Put fluoridated salt on sale in all current package sizes, so that the housewife is not tempted to buy unfluoridated salt because she does not like a certain package size; this measure increased the market share of F-salt from $58 \%$ in October-November-December 1993 to 84\% in April-MayJune 1994 (see Fig. 2 in Marthaler (17)).

- Limited access to unfluoridated salt: the "official" or "regular" salt would be fluoridated: this situation actually exists in several Latin American countries, for example in Jamaica, Costa Rica and Colombia. Legislation may be passed allowing unfluoridated (and/or uniodized) salt to be available exclusively in pharmacies or else in organic food shops.

- Higher concentrations of fluoride in the salt. This would also increase the effectiveness of an already functioning salt fluoridation scheme, but it would not increase the percentage of those who use the fluoridated salt. The possibility of covering the highest possible percentage, however, is a primary aim of any project. Toth (18) for example was aware that 250 ppm F is too low when fluoride is added exclusively to domestic salt. In the final years of his studies, he used exclusively salt with $350 \mathrm{ppm}$ F.

These changes could be attained at minimal cost. Increasing the percentage of users by using public relations firms, as in Germany, would be much more costly. It is indispensable for the medical community to receive excellent documentation on the benefits and safety of the fluoride added to salt. In view of the trend for lowering salt intake, the public should be informed clearly that fluoridated salt is the only type of salt recommended for use in all normal households. In highly industrialized countries, an increasing percentage of food is industrially processed whereby salt is often added; in addition, bouillon cubes and many other spices replace simple cooking salt. In fact, the consumption of plain salt is decreasing slowly but steadily.

\section{Conclusion}

Fluoridated salt has enormous potential in controlling dental caries. It is cheaper than any other method of caries prevention applicable to millions. Nevertheless, the current trend in academic dentistry is to rely almost exclusively on the topical effectiveness of fluoride-containing dentifrices to attain better dental health. However, only one or at most two billion of the world's population have access to high quality dentifrices, can afford them and have sufficient instruction and discipline in toothbrushing. The fluoride in dentifrice will reach the tooth surfaces to be protected only when a certain level of oral hygiene is obtained. For the majority of people in the world, this situation is unlikely to change in the next decades.

The cost of a fluoride-containing dentifrice is at least $5 €$ per year and person (the cost of the toothbrush may be categorized as being paid for by maintaining gingival and periodontal health). For fluoride reaching the tooth from salt in food, the cost is 
less than $0.05 €$, a ratio of $1 / 10,000$. Assuming that fluoride in dentifrices is four times more effective than salt fluoridation, the cost ratio is still favorable: $1 / 2,500$. Of course, fluoridation of salt and dentifrices are not alternatives - they should be used in combination. It is well documented that 55-60 million Germans and Swiss and more than 160 million people in Latin America benefit from the combined use of both fluoridated salt and fluoride toothpastes.

Salt fluoridation is legal in the EU, and is suggested by WHO (Resolution WHO 60-17) when water fluoridation cannot be implemented for whatever reason. In continental Europe, there are $25 \mathrm{EU}$ countries with a total population of around 330 million (Great Britain and the Irish Republic both have water fluoridation policies). Eight of these countries, with a total population of 200 millions, already have at this time the technical means to produce fluoridated salt. Accordingly, the total number of 200 million inhabitants of these countries could all at once benefit from the already existing machinery. While the oral health situation is slowly improving in some of the modernized countries, the introduction of salt fluoridation in combination with fluoridecontaining dentifrices would accelerate this favorable development.

Dental treatments are still expensive. The cost of dentistry has hardly been reduced, even in countries where the decline in caries began 30 years ago. Extension of preventive dentistry is still indispensable for improving oral health, also from a financial viewpoint. Last but not least, salt fluoridation offers a realistic potential to ameliorate dental health in the poorer regions of the world.

Acknowledgement: The author would like to thank Dr. George M. Gillespie, University College Hospital, London, and former Director Oral Health at the Pan American Health Organization/WHO for providing information about Latin America and reading critically this review.
Conflict of interest: The author declares that he has no conflict of interest.

\section{References}

1. Marine D, Kimball OP. The prevention of simple goiter. J Lab and Clin Med. 1917;3:40-5.

2. Wespi HJ. 40 years of goiter prevention with fluoridated salt [40 Jahre Kropfprophylaxe mit jodiertem Salz]. Bulletin des Eidg. Gesundheitsamtes 1962; Beilage B, Nr.2

3. Wespi HJ. Some thoughts about optimal nutrition during gravity [Gedanken zur Frage der optimalen Ernährung in der Schwangerschaft] Schweiz. Med Wochenschrift. 1948;78:153-7.

4. Wespi HJ. Fluoridated salt for caries prevention [Fluoridiertes Kochsalz zur Cariesprophylaxe]. Schweiz med Wochenschr. 1950;80:561-4.

5. Marthaler TM, Steiner M. Cariostatic results in the Canton of Glarus 4 years after the introduction of fluoridated salt [In German]. SSO Schweiz Monatsschr Zahnheilkd. 1981;91(1):9-20.

6. Dean HT. Endemic fluorosis and its relation to dental caries. Public Health Rep. 1938;53:1443-52.

7. Dean HT, Jay P, Arnold FA Jr., McClure FJ, Elvove E. Domestic water and dental caries, pincluding certain epidemiological aspects of oral L. acidophilus. Public Health Rep. 1939b;54:862-88.

8. Arnold FA Jr. Fluoride in drinking water: Its effect on dental caries. J Am Dent Assoc. 1948;36:28-36.

9. Marthaler TM, Meyer J, Bürgi H. The change from water to salt as the main vehicle for communitywide fluoride in Basle. Community Dent Oral Epidemiol. 2003;31:401-2.

10. DeCrousaz P, Marthaler TM, Menghini G, Steiner M. Fluoridation of salt in Switzerland [Fluoration du sel alimentaire en Suisse]. Réal Clin. 1993;4:343-50.

11. Marthaler TM, Steiner M. Caries-statistical results in the Canton of Glarlus, four years after the introduction of fluoridated salt [Kariesstatistische Ergebnisse im Kanton Glarus, vier Jahre nach Einführung fluoridierten Salzes]. Schweiz Monatsschr Zahnheilk. 1981;91:9-20.

12. Marthaler TM, Petersen PE. Salt fluoridation - an alternative in automatic prevention of dental caries. Int Dent J. 2005;55:351-8.

13. Marthaler TM. Overview of salt fluoridation in Switzerland since 1955, a short history. Schweiz Monatsschr Zahnmed. 2005;115:651-5.

14. Menghini G, Marthaler TM, Steiner M, Bandi A, Schürch E. Caries prevalence and ginigval inflammation in recruits in 1985; effects of preven- 
tion [Kariesprävalenz und gingivale Entzündung bei Rekruten im Jahre 1985: Einfluss der Vorbeugung]. Schweiz Monatsschr Zahnmed. 1991;101:1119-26.

15. De Crousaz P. Observations regarding enamel opacities in Switzerland related to fluoridation of drinking water and alimentary salt [Beobachtungen über Schmelzopazitäten in der Schweiz im Zusammenhang mit der Trinkwasserfluoridierung oder der Salzfluoridierung]. Schweiz Monatsschr Zahnheilk. 1982;92:332-44.

16. Thylstrup A, Fejerskov. Clinical appearance of dental fluorosis in permanent teeth in relation to histologic changes. Comm Dent Oral Epidemiol. 1978;6:315-8.

17. Steiner M, Menghini G. Asssessment of dental fluorosis prevalence in Swiss populations. Schweiz Monatsschr Zahnmed. 2010;120:12-20.

18. Marthaler TM, Steiner M, Menghini G, Sener B, De Crousaz P. Urinary Fluoride Excretion in Children With Low Fluoride Intake or Consuming Fluoridated Salt. Caries Res. 1995;29:26-34.

19. Toth K. Caries prevention by domestic salt fluoridation. Budapest: Akademiai Kiado; 1984.

20. Radnai M, Fazekas A. Caries prevalence in adults seven years after previous exposure to fluoride in domestic salt. Acta Med Dent Helv. 1999;4:163-6. [in: Schweiz Monatsschr Zahnmed Vol. 109, No. 10, October 1999]

21. Tramini P. Salt Fluoridation in France since 1986. Schweiz Monatsschr Zahnmed. 2005;115:656-8.

22. Schulte AG. Salt fluoridation since 1991. Schweiz Monatsschr Zahnmed. 2005;115:659-62.
23. Marthaler TM, Gillespie G, Götzfried F. Salt fluoridation in Europe - with potential worldwide. Kali und Steinsalz. 2011;Heft 3:2-15

24. Gillespie G, Roviralta G, eds. Salt fluoridation. Scientific Publication No. 501 of the Pan American Health Organization. Washington D.C.: the Regional Office of the World Health Organisation; 1986.

25. Mejia R, Espinal F, Velez H, Aguirre M. Resultados obtenidos de 1864-1972, Fluoruracion de la sal. Scientific and Technical Publication No. 615 of the Pan American Health Organizaion. Washington D.C.: the Regional Office of the World Health Organization; 2005.

26. Estupinan SR, Baez RJ, Horowitz H, Warpeha R, Sutherland B, Thamer M. Salt fluoridation and dental caries in Jamaica. Community Dent Oral Epidemiol. 2001;29:247-52.

27. Warpeha R, Beltran-Aguilar E, Baez R. Methodological and Biological factors Explaining the Reduction in Dental Caries in Jamaican School Children between 1984 and 1995. Pan American Journal of Public Health. 2001;10(1):37-44.

28. Baez RJ, Marthaler TM, Baez MX, Warpeha RA. Urinary fluoride levels in Jamaican children in 2008, after 21years of salt fluoridation. Schweiz Monatsschr Zahnmed. 2010;120:21-8.

29. Estupinan S. Promoting Oral Health: the use of salt fluoridation to prevent dental caries. Scientific and Technical Publication No. 615 of the Pan American Health Organizaion. Washington D.C.: the Regional Office of the World Health Organization; 2005.

30. Gillespie GM, Marthaler TM. Cost Aspects of Salt Fluoridation. Schweiz Monatsschr Zahnmed. 2005;115:778-84. 